This item was submitted to Loughborough's Research Repository by the author.

Items in Figshare are protected by copyright, with all rights reserved, unless otherwise indicated.

\title{
Briefing: holistic assessment of sustainable urban development
}

PLEASE CITE THE PUBLISHED VERSION

http://dx.doi.org/10.1680/udap.2010.163.3.101

\section{PUBLISHER}

(c) Institution of Civil Engineers

\section{VERSION}

VoR (Version of Record)

\section{PUBLISHER STATEMENT}

This work is made available according to the conditions of the Creative Commons Attribution-NonCommercialNoDerivatives 4.0 International (CC BY-NC-ND 4.0) licence. Full details of this licence are available at: https://creativecommons.org/licenses/by-nc-nd/4.0/

\section{LICENCE}

CC BY-NC-ND 4.0

\section{REPOSITORY RECORD}

Paranagamage, Primali, Andrew D.F. Price, and Fahmida Khandokar. 2019. "Briefing: Holistic Assessment of Sustainable Urban Development”. figshare. https://hdl.handle.net/2134/23524. 

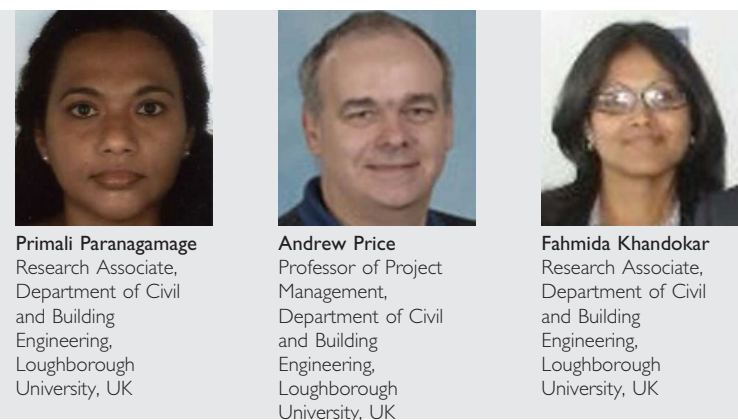

\title{
Briefing: Holistic assessment of sustainable urban development
}

\author{
P. Paranagamage MSc, PhD, A. Price PhD, CEng, FICE, FCIOB, DSc and F. Khandokar MEngSc, BURP
}

Introducing the SUE-MoT (metrics, models and toolkits for whole-life sustainable urban development) series, this paper highlights some of the barriers that need to be addressed if the vision for holistic assessment is to be realised. The complexities of sustainability assessment raised in this paper will be further discussed in detail in the SUE-MoT series of papers that will be published in forthcoming issues of this journal. This paper highlights the priorities to address when assessment tools are presented to decision makers of urban development projects. This discussion is limited to the issues, values and solutions in the UK context.

\section{INTRODUCTION}

The sustainable urban environment (SUE) programme is a major initiative supported by the Engineering and Physical Sciences Research Council (EPSRC). It aims to promote sustainable urban development for the twenty-first century through research, strengthening capabilities to address sustainability issues and engaging with end users (Issues, 2010). The SUE-MoT project - metrics, models and toolkits for whole-life sustainable urban development, EPSRC grant no. GR/S18311/01- a consortium of four academic (Loughborough, Dundee, Glasgow Caledonian and St Andrew's Universities) and several industrial partners, aims to promote sustainable development by providing models and toolkits for all decision makers associated with urban development (SUE-MoT, 2010).

\section{NEED FOR PROTOCOLS}

The urban built environment is a key determinant of the quality of life of its inhabitants, the ultimate goal of sustainable development. The design of urban environments must be guided by consistent protocols illuminating attendant issues to enable decision makers and planners to gather, compile and analyse data in a way that supports sustainable planning and design (UN CSD, 2001). In response to this need, the SUE-MoT project developed a comprehensive and transparent framework that encouraged key decision makers to systematically assess the sustainability of urban developments at all scales, locations and contexts, taking into account stakeholder values.

\section{THE SUE-MOT SERIES}

Conferences took place in 2007 and 2009 to bring together international researchers, professionals, tool developers, policy makers and other stakeholders involved in the field of urban sustainability assessment to exchange ideas and knowledge on how to meet the assessment needs of urban decision makers (Figures 1 and 2). At the 2009 conference, 75 papers were presented on the themes of

(a) urban planning and design for sustainability

(b) sustainable buildings

(c) design, performance and assessment

(d) quality of life in the urban environment

(e) stakeholder participation

(f) urban sustainability and the move to low-carbon developments

(g) measures, assessment theory, complexity and uncertainty.

\section{HOLISTIC ASSESSMENT}

The SUE-MoT scoping study of nearly 700 sustainability assessment tools examined their key roles, scope and depth of impacts assessed, applicability to the scale and location of assessment, the life-cycle phases of development assessed, stakeholder involvement and availability of data. The results of the scoping study confirmed that there was no assessment tool that was sufficiently inclusive, holistic, multi-dimensional and capable of addressing social, environmental and economic issues simultaneously (El-Haram et al., 2007). Although the complexities of developing such a tool were not underestimated, one of the main objectives of SUE-MoT was to develop an integrated sustainability assessment toolkit. Integrated assessment has been described as 'a structured process of dealing with complex issues, using knowledge from various scientific disciplines and/or stakeholders, such that integrated insights are made available to decision makers' (Rorarius, 2007). Such a tool should be capable of assessing the sustainability of urban developments at any scale - from component through to complete development - and for all stages of their life-cycles.

\section{QUESTION OF SCALE}

Urban development involves a variety of scales, which in turn involves a multiplicity of systems and sub-systems, and assessment needs vary with each context. There is thus a need for a systematic approach that allows assessments to be undertaken at a variety of scales (Figure 3). The scale could range from a whole city, part of a city, buildings, building components or a particular building material. A part of a city may need to be assessed when its characteristics - such as 


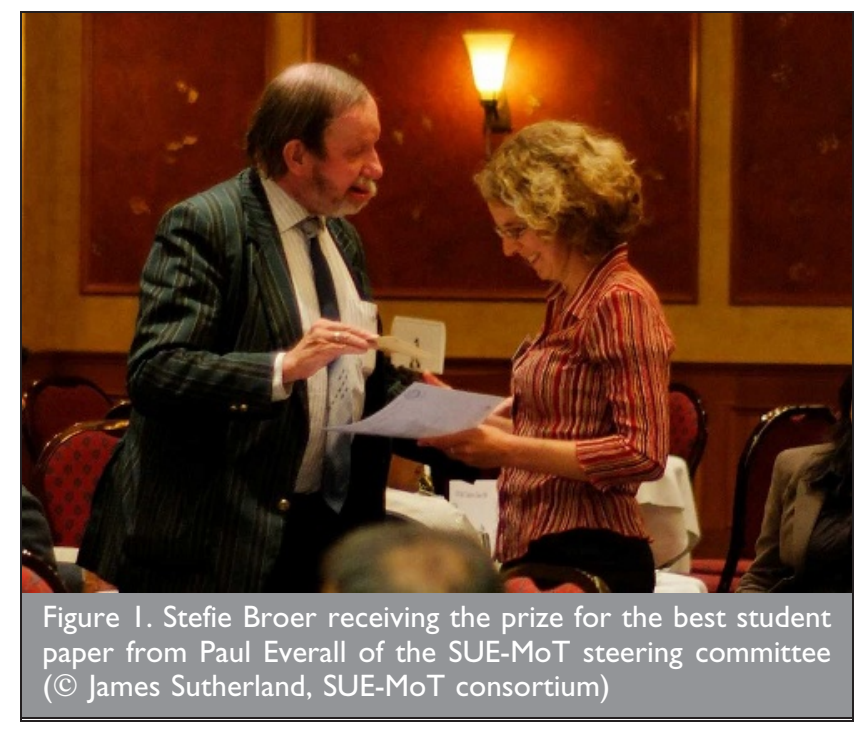

location, principal function or sense of community - are unique. A building may need to be assessed depending on its function and assembly of components

\section{QUESTION OF THE AIMS}

Assessment may mean not only mitigating negative impacts but also making a positive contribution to sustainable development to improve quality of life (Pope et al., 2004). As such, decision makers may undertake an 'assessment' for a range of purposes, for example

(a) To help them identify relevant sustainability impacts for a project (e.g. to produce a scoping matrix of all possible impacts such as an environmental impact assessment (EIA)).

(b) To predict the impact of a project on a particular issue (e.g. energy).

(c) To guide the planning or design process in relation to its performance on one or more impacts (e.g. to receive guidance on design features to minimise energy use).

(d) To assess a plan or design overall in relation to one or more impacts (e.g. Building Research Establishment environmental assessment method (BRE, 2009).

(e) To monitor the performance of a project when in use.

\section{QUESTION OF IMPACTS}

Considering a triple bottom line approach, a sustainability assessment needs environmental impacts to be better known for

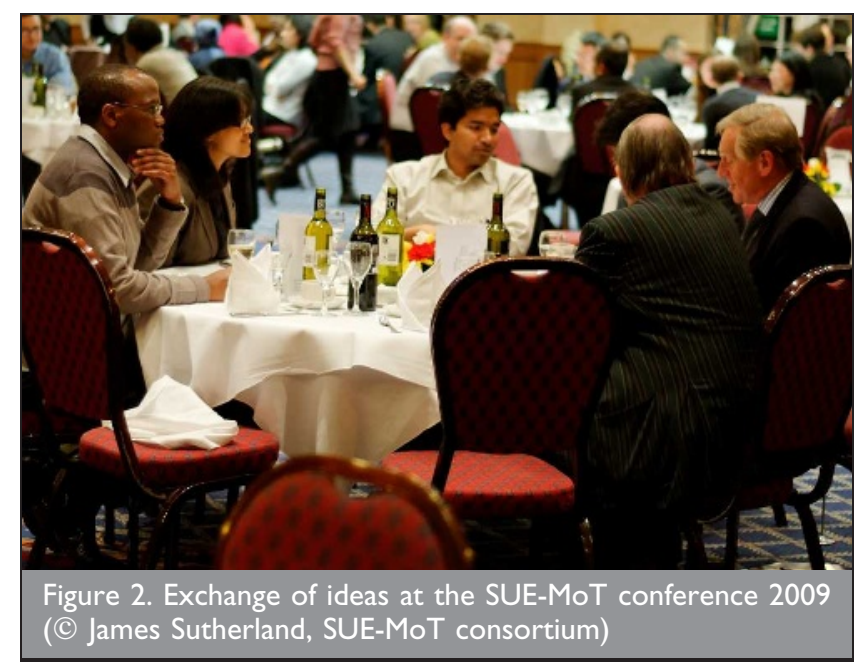

inputs of materials use, water use, energy use and land take and for outputs such as pollution to air, climate, land and water, waste produced, local bio-physical assets, and environmental quality (Figure 4).

The scope and meaning of economic impacts in relation to sustainability is unclear in definition, but may cover whole-life costs and economic multiplier effects (including local commercial activity and employment). Whether property values, the costs of goods and inflation are to be included as sustainable indicators is still in debate. Forbes et al. (2010) address issues on understanding the assessment of economic sustainability and tool development in this direction.

There is also ambiguity as to how the contribution of social sustainability may be assessed. That is, whether social impacts can be considered

(a) an outcome of environmental and economic sustainability (Assefa and Frostell, 2007)

(b) as related to social outcomes such as equity, poverty reduction and livelihood

(c) an outcome of 'softer issues' such as 'wellbeing' and 'happiness' (Galloway et al., 2005)

(d) a result of relations between people, understood as the formal and informal rules that govern the behaviour of organisations and individuals (Ashcroft, 2009).

The nature, degree and extent to which generic considerations for social sustainability such as health, crime, security, employment, education, transport, heritage or social capital are dependent on buildings and surroundings have not been understood in objective terms, which poses a significant barrier to holistic assessment. Colantonio (2010) contributes towards this debate.

\section{BARRIERS TO HOLISTIC ASSESSMENT}

Given the aspirations of holistic assessment of sustainable urban development, some of the gaps that need to be bridged can be summarised as follows.

(a) Tools to guide sustainable development - particularly for larger objects of assessments such as cities or parts of cities - are not well developed. In current practice, decision makers use 'checklists' intended for rating designs or plans as tools to guide the planning process. However, when used as sustainability guidance this method cannot serve well because checklists do not illuminate the relationship between recommended action and intended results. Being written for other objectives, such documents do not cover all impacts, nor is the relationship between sustainability impacts and recommended action explicitly stated. For the decision maker, the value of such tools as guidance for sustainability may not, therefore, be transparent. Existing urban design and planning guidance that captures the conditions and culture of the UK can be useful to initiate step change, particularly to guide social sustainability and its assessment.

(b) Frameworks that bring together knowledge on the range of issues to be assessed at multiple scales of urban development, as adapted to UK conditions, may provide a direction towards developing comprehensive guidance; for example the Green matrix in the USA (Green Matrix, 2010). Thomson 


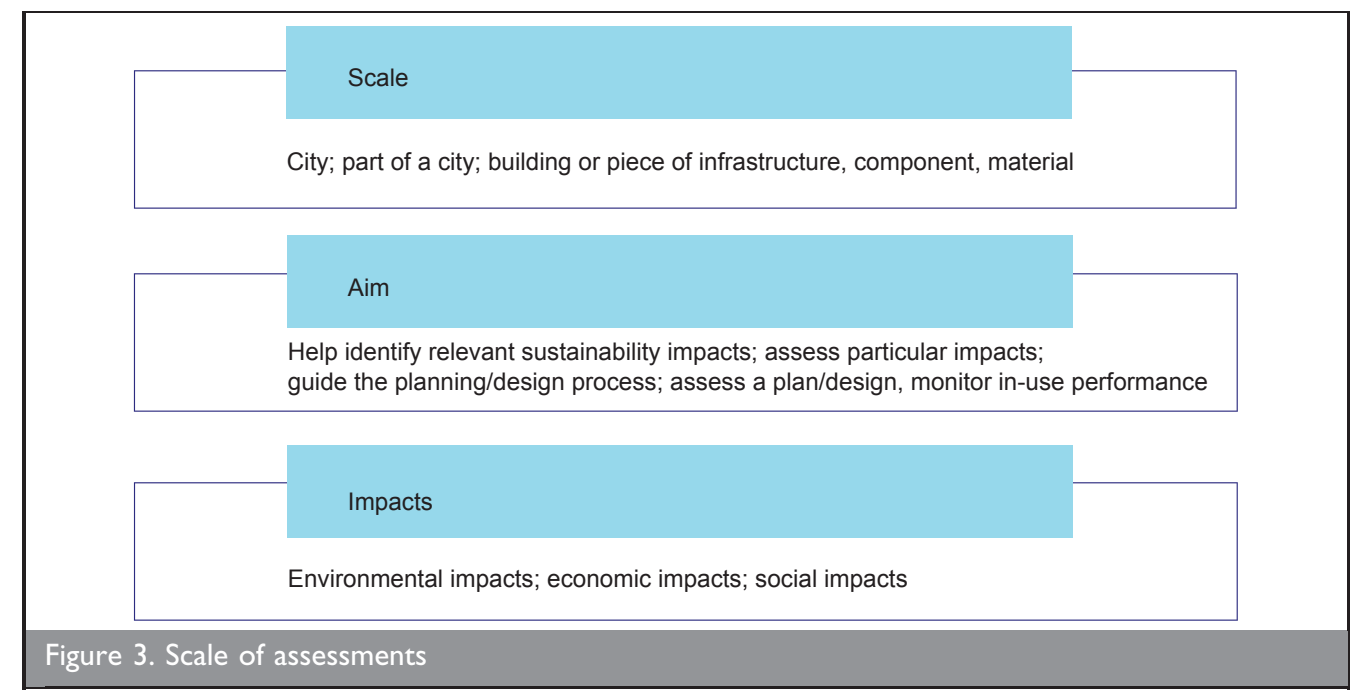

et al. (2010), capture knowledge from UK experiences and help identify directions in this area.

(c) The overall assessment of building design has largely concentrated on impacts defined by rating systems. While such ratings provide comparative indicators of environmental sustainability, the social and economic components of rating systems are yet to be informed by research on how non-quantifiable sustainability issues can be benchmarked or measured by proxy. There is an acute knowledge gap to be filled in this regard, which perhaps is also reflected in the absence of tools with which to measure social and economic impacts.

(d) Problems in the vision of holistic assessment also arise from tool boundaries. Although a holistic assessment of sustainability requires results of assessment to be viewed in a common framework, results from different tools are not comparable because their boundaries differ according to what is included and excluded in the analysis, how cause and effect chains are constructed in the models, how choices are framed for particular users and how

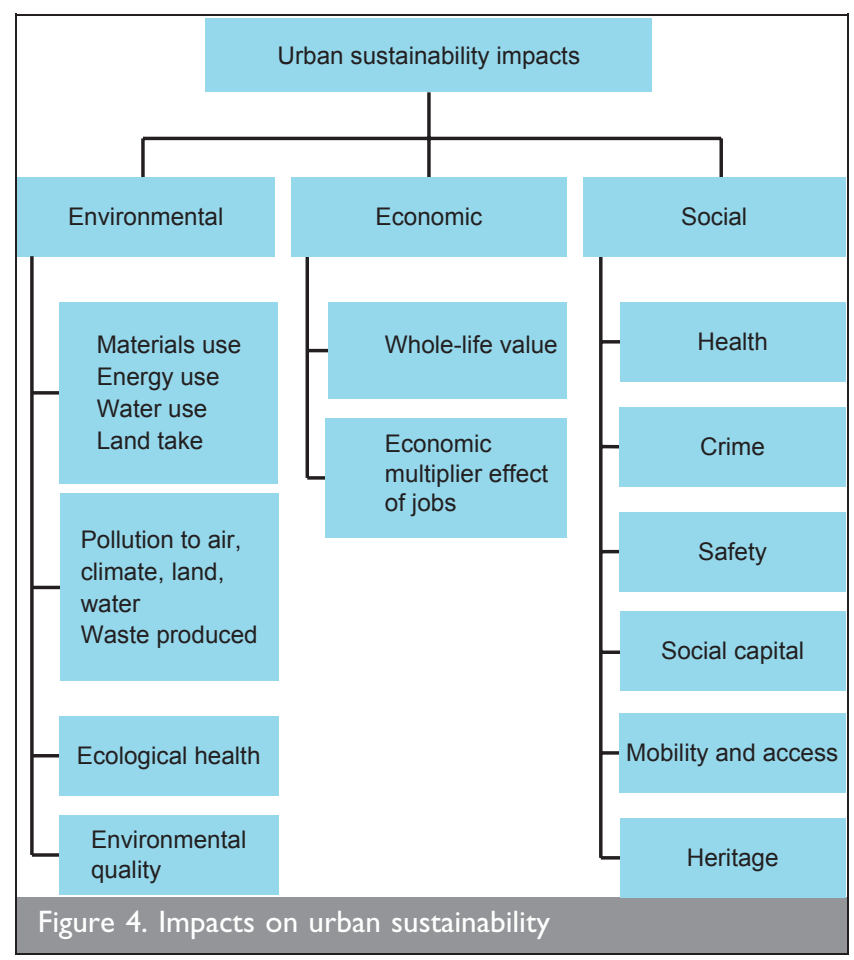

results are segregated and aggregated. The analysis that underpins the scores may not be comparable as the scoring processes employ different procedures. While some tools translate objective data analysis to standards that can be consulted and this affects the scores, other tools cover a broader range of impacts with scoring being linked to consensus-based assessment. Therefore, the scores from two assessments might not be comparable even for similar impacts.

(e) Visions for holistic assessment also depend on the accessibility of tools with regard to a user's needs. For example, decisionsupport tools provide detailed guidance on selected environmental impacts at building scale and are usually modelled on expert technical knowledge. These have a strong focus on a specific area of concern (e.g. life-cycle costs, operating energy, lighting) or a combination of effects. Whole-building assessment frameworks provide a broader coverage of environmental, economic and social issues of sustainability and use a mix of objective and subjective data. From the point of view of the user, being able to have a complete assessment from one tool is ideal, and this could be a reason why tools that are primarily intended to produce a rating are often used to guide a design. However, there are problems in that the levels of guidance that decision-support tools provide for selected impacts cannot be compared with guidance given by assessment frameworks. To consider a single impact, a user of Ecotect (2008) (an environmental analysis tool used to simulate building performance) requires expert knowledge on designing for daylight to arrive at alternative design options, while the Code for Sustainable Homes (BRE, 2009) addresses natural lighting in a way that does not require in-depth knowledge of the subject. As such, certain tools have converted technical knowledge into standards while others engage the user with technicalities. As the purpose of the tools therefore can range widely, some tools meet more than one of the aims of assessment and could be used for a variety of purposes but may not fulfil the same degree and depth as a tool designed for a particular aim. The question therefore is how to address the issue of a user or decision maker wanting to select a range of tools to assess or to have guidance for a range of impacts in a single assessment. If this means that successful assessment depends on the expertise of the user and expected outcome, recommendation of tools to a decision maker would need to consider this as a key criteria. Work by Isaacs et al. 
(2010) may address possible future directions of attuning tools to stakeholder needs.

The complexity of assessments and the intricacies involved arising from the needs of each context should be seen at the very start of an assessment so that users can make an informed decision about which method to use by knowing the complexity of a tool, what it can do, the nature of data required, the level of expertise required to use it and the results it produces. Despite the gaps that exist, it is hoped that the SUE-MoT research will highlight issues for further development of the field.

\section{REFERENCES}

Ashcroft J (2009) Social Sustainability: A Relational Approach to Reporting and Assessment. Relationships Foundation, Cambridge, UK.

Assefa G and Frostell B (2007) Social sustainability and social acceptance in technology assessment: a case study of energy technologies. Technologies in Society 29(1): 63-78.

BRE (Building Research Establishment) (2009) BREEAM: Code for Sustainable Homes. See http://www.planningportal.gov. uk/uploads/code_for_sustainable_homes_techguide_oct08. pdf for further details (accessed 10/01/2009).

Colantonio A (2010) Urban social sustainability themes and assessment methods. Proceedings of the Institution of Civil Engineers, Urban Design and Planning 163(2): 79-88, doi: 10.1680/udap.2010.163.2.79.

Ecotect (2008) www.squ1.com/archive/ecotect/tutorials/tutorials. htm (accessed 27/07/2010).

El-Haram M, Walton JS, Horner RWM, et al. (2007) Development of an integrated sustainability assessment toolkit. Proceedings of SUE-MoT International Conference on Whole Life Urban Sustainability and its Assessment, Glasgow.
Forbes D, El-Haram M, Smith S and Horner M (2010) Incorporating an economic measure in sustainability assessment. Proceedings of the Institution of Civil Engineers, Urban Design and Planning, in press.

Galloway S, Birkin N, Hamilton C and Petticrew M (2005) Quality of Life and Well-being: Measuring the Benefits of Culture and Sport: Literature Review and Think Piece. Education Department Research Programme, Edinburgh, UK.

Green matrix (2010) See www.greenmatrix.net (accessed 24/06/ 2010).

Isaacs J, Falconer R, Gilmour D and Blackwood D (2010) Enhancing urban sustainability using 3D visualisation. Proceedings of the Institution of Civil Engineers, Urban Design and Planning, in press.

Issues (2010) See http://www.urbansustainabilityexchange.org. uk/ISSUESSueProgramme.htm (accessed 24/06/2010).

Pope J, Annandale D, Morrison and Saunders A (2004) Conceptualising sustainability assessment. Environmental Impact Assessment Review 24(6): 595-616.

Rorarius J (2007) Existing Assessment Tools and Indicators: Building up Sustainability Assessment (Some Perspectives and Future Applications for Finland). Ministry of the Environment, Kasarmikatu, Finland.

SUE-MoT (2010) See www.SUE-mot.org (accessed 24/06/2010).

Thomson CS, El-Haram MA and Emmanuel R (2010) Mapping knowledge flow during sustainability assessment. Proceedings of the Institution of Civil Engineers, Urban Design and Planning 163(2): 67-78, doi: 10.1680/ udap.2010.163.2.67.

UN CSD (United Nations Commission for Sustainable Development) (2001) Commission on Sustainable Development, Report on the Ninth Session. UN CSD, New York.

\section{What do you think?}

To discuss this briefing, please email up to 500 words to the editor at journals@ice.org.uk. Your contribution will be forwarded to the author(s) for a reply and, if considered appropriate by the editorial panel, will be published as discussion in a future issue of the journal.

Proceedings journals rely entirely on contributions sent in by civil engineering professionals, academics and students. Papers should be 2000-5000 words long (briefing papers should be 1000-2000 words long), with adequate illustrations and references. You can submit your paper online via www.icevirtuallibrary.com/content/journals, where you will also find detailed author guidelines. 